\title{
Influência do cultivo em consórcio na produção de fitomassa e óleo essencial de manjericão (Ocimum basilicum L.) e hortelã (Mentha x villosa Huds.)
}

\author{
MAIA, J.T.L.S.*; MARTINS, E.R.; COSTA, C.A.; FERRAZ, E.O.F.; ALVARENGA, I.C.A.; SOUZA JÚNIOR, I.T.; \\ VALADARES, S.V. \\ Universidade Federal de Minas Gerais - Caixa Postal 135 - CEP 39.404-006 - Montes Claros, MG * janinitatimaia \\ @yahoo.com.br
}

\begin{abstract}
RESUMO: As plantas medicinais produzem seus princípios ativos de acordo com os estímulos do ambiente, por isso a presença de outras plantas pode comprometer a produção dos metabólicos secundários. Assim, o presente trabalho teve como objetivo avaliar o efeito do cultivo consorciado sobre a produção de fitomassa e o teor de óleo essencial de manjericão (Ocimum basilicum L.) e hortelã (Mentha $x$ villosa Huds.). O experimento foi conduzido na área experimental do Núcleo de Ciências Agrárias da Universidade Federal de Minas Gerais, Campus Regional de Montes ClarosMG. O delineamento utilizado foi o de blocos casualizados, com doze repetições, compreendendo seis tratamentos: manjericão + cenoura, manjericão + alface, manjericão solteiro, hortelã + cenoura, hortelã + alface e hortelã solteira. A produção de fitomassa e óleo essencial da hortelã não foram influenciados pelos tratamentos. Para o manjericão, apenas a massa fresca variou significativamente com os tratamentos.
\end{abstract}

Palavras-chave: plantas medicinais, metabólitos secundários, consórcio

\begin{abstract}
Influence of intercropping on phytomass and essential oil production in basil (Ocimum basilicum L.) and mint (Mentha $x$ villosa Huds.). Medicinal plants produce their active principles according to environmental stimuli; thus, the presence of other plants may affect the synthesis of secondary compounds. The present work aimed to evaluate the effect of intercropping on phytomass and essential oil production in basil (Ocimum basilicum L.) and mint (Mentha $x$ villosa Huds.). The study was carried out in the experimental field of the Center for Agriculture, Federal University of Minas Gerais, Montes Claros Campus, Minas Gerais State, Brazil. The experimental design was in randomized blocks, with twelve replicates and six treatments: basil + carrot, basil + lettuce, sole crop of basil, mint + carrot, mint + lettuce, and sole crop of mint. Phytomass and essential oil production in mint were not affected by the treatments. As regards basil, only fresh matter significantly varied with treatments.
\end{abstract}

Key words: medicinal plants, secondary metabolites, intercropping

\section{INTRODUÇÃO}

O mercado mundial de medicamentos fitoterápicos movimenta em torno de US $\$ 22$ bilhões ao ano (França, 2000), resultado do aumento do interesse pelo consumo de medicamentos à base de plantas e complementos alimentares, e da busca por hábitos de vida mais saudável (Corrêa et al., 2004). O manjericão (Ocimum basilicum L.), espécie originária da Índia, é usado como estimulante digestivo, antiespamódico, e antisséptico (Martins et al., 2000), sendo comercialmente cultivado como aromatizante ou tempero (Blank et al., 2005). O óleo essencial da hortelã (Mentha x villosa Huds.) possui grande valor comercial, sendo utilizado na indústria de produtos higiênicos, de alimentos e de fármacos, possuindo atividade fungicida (Maia, 1998). Assim, manjericão e hortelã se tornam espécies com potencial de mercado, pois já se encontram na literatura vários estudos na área fitoquímica, consideravelmente bem avançados sobre as duas espécies, além dos aspectos fitotécnicos que vêm sendo pesquisados, já vez que fatores como nutrição, intensidade luminosa, solo, presença de outras plantas, dentre outros pontos, comprometem a qualidade química de espécies medicinais (Corrêa

Recebido para publicação em 12/02/2008

Aceito para publicação em 30/11/2008

Rev. Bras. PI. Med., Botucatu, v.11, n.2, p.137-140, 2009. 
Júnior et al., 1994).

No entanto, é necessário intensificar os estudos sobre as formas de cultivo de ervas medicinais, uma vez que é crescente o interesse do mercado. Algumas pesquisas vêm sendo desenvolvidas no sentido de se obterem informações sobre o comportamento destas espécies terapêuticas. Innecco et al. (2003), estudando o espaçamento, época e número de colheitas em hortelã (Mentha $x$ villosa), verificaram que a produção de massa seca, óleo essencial e óxido de piperitenona aumentaram conforme o aumento do espaçamento entre plantas $(0,15 ; 0,20$ e $0,35 \mathrm{~m})$. Segundo Singh (2002), ao avaliar o efeito da irrigação e do nitrogênio na qualidade do manjericão (Ocimum basilicum), verificou que doses de $200 \mathrm{~kg} \mathrm{ha}^{-1} \mathrm{de} \mathrm{N}$, resultaram em maior rendimento de biomassa e óleo essencial.

Em um contexto equivalente, a olericultura vem, ao longo das últimas décadas, buscando alternativas de produção com o objetivo de garantir retorno econômico, ofertar produtos com melhor qualidade e com menor impacto ao ambiente (Rezende et al., 2005). Uma das técnicas que podem favorecer tais objetivos é o cultivo consorciado (Cecílio Filho \& May, 2002), que vem demonstrando efeitos satisfatórios em relação ao controle de plantas espontâneas, controle de pragas e doenças, uso adequado da terra, manutenção da biodiversidade local e aumento da produtividade total (Vieira, 1989; Caetano et al., 1999; Müeller et al., 1998).

Diante do exposto, o presente trabalho teve como objetivo verificar o efeito do cultivo consorciado sobre a produção de óleo essencial e fitomassa de manjericão e hortelã.

\section{MATERIAL E MÉTODO}

O experimento foi realizado na área experimental do Núcleo de Ciências Agrárias da Universidade Federal de Minas Gerais, Campus Regional de Montes Claros - Minas Gerais (NCA/ UFMG), no período de maio a setembro de 2007. De acordo com a classificação Köppen, o clima da região é tipo tropical de savana, com inverno seco e verão chuvoso. O solo é tipo Cambissolo Háplico com as seguintes características químicas: $\mathrm{pH}$ em água $=7,3$; Matéria orgânica $=3,39 \mathrm{~g} \mathrm{dm}^{-3} ; \mathrm{P}=33,8 \mathrm{mg} \mathrm{dm}^{-3} ; \mathrm{K}=$ $240 \mathrm{mg} \mathrm{dm}^{-3} ; \mathrm{Al}=0,00 \mathrm{cmol}_{\mathrm{c}} \mathrm{dm}^{-3} ; \mathrm{Ca}=7,40 \mathrm{cmol}_{\mathrm{c}}$ $\mathrm{dm}^{-3} \mathrm{e} \mathrm{Mg}=2,0 \mathrm{cmol}_{\mathrm{c}} \mathrm{dm}^{-3}$.

O delineamento experimental utilizado foi em blocos casualizados com seis tratamentos e doze repetições. Foram utilizadas as cultivares de alface (Lactuca sativa L.) 'Grand rapids' e cenoura (Daucus carota L.) 'Brasília'. Os tratamentos consistiram no cultivo consorciado manjericão + cenoura e manjericão + alface, hortelã + cenoura e hortelã + alface, além dos cultivos em solteiro de cada planta medicinal. As parcelas tiveram 1,0 $\mathrm{m}$ de largura por $1,5 \mathrm{~m}$ de comprimento, com quatro linhas de plantas nos canteiros, nos monocultivos, e duas linhas de planta nos consórcios, sendo que a parcela útil foi constituída por uma área de $0,60 \times 0,30 \mathrm{~m}$. O espaçamento foi de $0,30 \mathrm{~m}$ entre plantas e $0,30 \mathrm{~m}$ entre linhas, sendo que para a cenoura, após o desbaste, foi de 0,05 m entre linhas.

As mudas das plantas medicinais foram obtidas por estaquia a partir de matrizes do Horto Medicinal do NCA/UFMG, e produzidas em casa de vegetação, em bandejas de isopor de 128 células com substrato comercial. As mudas de alface foram produzidas em sementeiras, e a cenoura teve semeadura direta. Após o enraizamento, as mudas de manjericão e hortelã foram transplantadas ao campo, juntamente com as de alface, uma semana depois do semeio da cenoura.

Foi realizada somente adubação orgânica, com $35 \mathrm{t} \mathrm{ha}^{-1}$ de esterco bovino. A irrigação foi feita por micro-aspersão e durante a condução do experimento foram realizadas capinas manuais.

A colheita das plantas medicinais ocorreu em setembro de 2007, quando todas as hortaliças já haviam completado seus ciclos de produção. Avaliouse para o manjericão a massa fresca e seca, a altura de plantas e o teor de óleo essencial; na hortelã foi avaliada a massa fresca e seca e o teor de óleo essencial.

Para a extração do óleo essencial, foram utilizadas $100 \mathrm{~g}$ da parte aérea das plantas, as quais foram trituradas e submetidas ao método de hidrodestilação, utilizando-se o aparelho Clevenger modificado, por 3 horas. A quantidade de óleo foi separada do hidrolato e transferida para frascos, utilizando balança analítica para a obtenção das massas dos óleos. Os teores dos óleos obtidos foram calculados com base na matéria seca das plantas.

As variâncias apresentaram homogeneidade pelo teste de Cochran e Barttlet, e as distribuições foram normais pelo teste Lilliefors. Os dados foram analisados pelo programa SAEG (Sistema de Análise Estatística e Genética), desenvolvido pela Universidade Federal de Viçosa (versão 9.1), submetidos à análise de variância, e as médias comparadas pelo teste Tukey a $5 \%$ de probabilidade.

\section{RESULTADOE DISCUSSÃO}

Na Tabela 1 estão apresentados os valores médios obtidos para as variáveis analisadas para a hortelã. Não houve diferença significativa entre os tratamentos, evidenciando que é possível estabelecer o consórcio entre estas espécies com benefícios para ambas. Porém, tais porcentagens são inferiores às encontradas por Ramos et al. (2005) que observaram teor de óleo essencial de 1,25\%. 
TABELA 1. Massa fresca (MF), seca (MS), produção (Prod. Óleo) e teor de óleo essencial (Teor) da parte aérea em plantas de hortelã cultivadas solteiras e em consórcio com cenoura e alface.

\begin{tabular}{ccccc}
\hline Tratamentos & MF (g) & MS (g) & Prod. Óleo (g) & Teor (\%) \\
\hline Hortelã + Cenoura & $122,45^{\text {ns }}$ & $13,51^{\text {ns }}$ & $0,070^{\text {ns }}$ & $0,53^{\text {ns }}$ \\
Hortelã + Alface & $159,65^{\text {ns }}$ & $19,34^{\text {ns }}$ & $0,089^{\text {ns }}$ & $0,46^{\text {ns }}$ \\
Hortelã solteira & $154,25^{\text {ns }}$ & $19,13^{\text {ns }}$ & $0,099^{\text {ns }}$ & $0,53^{\text {ns }}$ \\
\hline CV (\%) & 18,09 & 23,06 & 20,58 & 23,71 \\
\hline
\end{tabular}

ns - não signficativo pelo teste Tukey a $5 \%$ de probabilidade.

Baixos valores na produção de óleos essenciais podem ter sido influenciados por deficiências no método de extração, bem como devido à alta umidade nas plantas frescas, favorecendo a aglutinação do óleo, o que impede que o vapor penetre de forma mais uniforme nos tecidos (Guenther, 1972). As características desejadas em planta terapêutica, são a fitomassa e o princípio ativo em questão, e se no cultivo consorciado obtém-se um aumento da produtividade do agroecossistema, e é mantida a biodiversidade local, favorecendo o controle natural de pragas e de doenças, além da reciclagem de nutrientes (Innis, 1997), a utilização de plantas medicinais associadas a hortaliças torna-se uma alternativa viável.

O fato de não ter havido prejuízos para a hortelã na produção de óleo essencial em cultivo consorciado, quando comparado com o cultivo solteiro, sugere que pode ter ocorrido uma complementaridade entre a hortelã e a alface. Esta complementação pode estar relacionada à evidência de que os sistemas ecológicos são capazes de realizar autoregulação, principalmente em sistemas de consórcio, onde as raízes exploram distintamente as profundidades de solo, ou competem por luz de formas diferentes (Santos, 1998), já que a hortelã é uma planta muito exigente nutricionalmente, sendo a proporção do óleo essencial alterada pelas condições nutricionais da planta (Maia, 1998).

$\mathrm{Na}$ Tabela 2 encontram-se dispostos os valores médios das variáveis analisadas no manjericão. Em relação à massa seca, teor de óleo essencial e altura das plantas, não foram observados efeitos significativos dos tratamentos, o que concorda com Vieira et al. (2005), que avaliando a produção de arruda e cenoura em cultivo solteiro e consorciado, em arranjos diferenciados, não observaram diferenças significativas na produção da arruda em nenhum dos tratamentos avaliados.

A produção de biomassa foi influenciada pelos tratamentos, sendo superior no consórcio manjericão e alface. Tais resultados diferem dos observados por Moraes et al. (2005), que consorciando capuchinha com repolho verde e roxo, observaram melhor produção da capuchinha no monocultivo.

Os resultados obtidos em relação ao teor de óleo essencial discordam dos observados por Blank et al. (2005), que ao avaliar a influência da adubação orgânica e mineral no cultivo de manjericão verificaram menor teor de óleo essencial na adubação com esterco bovino + adubo formulado $(0,32 \%)$.

Segundo Rodrigues \& Carvalho (2001), as variações nutricionais podem afetar a produção de óleo essencial, já que a síntese dos princípios ativos pode ser alterada conforme as técnicas de cultivo (Madueño-Box, 1973). Portanto, é necessária uma

TABELA 2. Massa fresca (MF), seca (MS), altura, produção (Prod. Óleo) e teor de óleo essencial (Teor) da parte aérea em plantas de manjericão cultivadas solteiras e em consórcio com cenoura e alface.

\begin{tabular}{cccccc}
\hline Tratamentos & MF (g) & MS (g) & Altura & Prod. Óleo (g) & Teor (\%) \\
\hline Manjericão + Cenoura & $248,10 \mathrm{~A}$ & $35,94^{\mathrm{ns}}$ & $64,74^{\mathrm{ns}}$ & 0,69 & $0,23^{\mathrm{ns}}$ \\
Manjericão + Alface & $368,10 \mathrm{~A}$ & $50,74^{\mathrm{ns}}$ & $64,74^{\mathrm{ns}}$ & 1,0 & $0,25^{\mathrm{ns}}$ \\
Manjericão solteiro & $217,00 \mathrm{~B}$ & $26,34^{\mathrm{ns}}$ & $60,93^{\mathrm{ns}}$ & 0,75 & $0,30^{\mathrm{ns}}$ \\
\hline CV (\%) & 25,19 & 36,93 & 14,22 & 32,13 & 11,27 \\
\hline
\end{tabular}

Médias seguidas pela mesma letra na coluna não diferem ao nível de $5 \%$ de probabilidade pelo teste Tukey. ${ }^{\text {ns }}$ não signficativo pelo teste Tukey a $5 \%$ de probabilidade. 
escolha minuciosa das culturas que irão compor os sistemas em consórcio, além das épocas de instalação das mesmas no campo, para explorar todas as vantagens deste sistema (Trenbath, 1975).

Para o manjericão, o consórcio favoreceu a produção de biomassa, sendo observada uma tendência para a redução na concentração de óleo essencial produzida, podendo ser resultado do efeito de diluição. Além disso, tal fato pode ser interpretado também como menor necessidade de metabólitos secundários relacionados à defesa (Carvalho et al., 2003), devido ao ambiente favorável oferecido pelo cultivo consorciado, que possibilita o envolvimento de plantas com diferentes ciclos e portes, reduz o crescimento de ervas espontâneas, regula a temperatura do solo, controla a erosão e otimiza a utilização de insumos agrícolas (Olasantan et al., 1996). Recomenda-se então a associação de espécies que melhor se adaptem uma às outras, no caso em questão manjericão e alface, onde foram observadas tendências de maiores valores de massa fresca, seca e altura de plantas, bem como a segunda maior tendência no teor de óleo essencial, 0,25\% (Tabela 2).

\section{CONCLUSÃO}

A produção de biomassa e de óleo essencial de hortelã não foi influenciada pelos tratamentos. $O$ consorcio favoreceu apenas a produção de massa fresca do manjericão.

\section{AGRADECIMENTO}

À Coordenação de Aperfeiçoamento de Pessoal de Nível Superior (Capes) e à Fundação de Amparo a Pesquisa do Estado de Minas Gerais (Fapemig), pelo suporte financeiro.

\section{REFERÊNCIA}

BLANK, A.F. et al. Influencia da adubação orgânica e mineral no cultivo de manjericão cv. Genovese. Revista Ciência Agronômica, v.36, n.2, p.175-8, 2005.

CAETANO, L.C.S.; FERREIRA, J.M.; ARAÚJO, M.L. Produtividade de cenoura e alface em sistema de consorciação. Horticultura Brasileira, v.17, n.2, p.1436, 1999.

CARVALHO, L.M. et al. Efeito de potências decimais da homeopatia de Arnica montana sobre as plantas de artemísia. Revista Brasileira de Plantas Medicinais, v.6, n.1, p.46-50, 2003.

CECÍLIO FILHO, A.B.; MAY, A. Produtividade das culturas de alface e rabanete em função da época de estabelecimento do consórcio. Horticultura Brasileira, v.20, n.3, p.501-4, 2002.

CORRÊA JÚNIOR, C.; MING, L.C.; SCHEFFER, M.C. Cultivo de plantas medicinais, condimentares e aromáticas. Jaboticabal: FUNEP, 1994. 162p.

CORRÊA, R.M. et al. Rendimento de óleo essencial e caracterização organolépticas de folhas de assa-peixe submetidas a diferentes métodos de secagem. Ciência e Agrotecnologia, v.28, n.2, p.339-44, 2004.

FRANÇA, A.L. Natura entra no setor farmacêutico. Gazeta Mercantil, n.2, p.8, 2000. Caderno C.

GUENTHER, E. The essential oils. Malabar: Krieger, 1972. 427p.

INNECCO, R. et al. Espaçamento, época e número de colheitas em hortelã-rasteira (Mentha $x$ villosa Huds). Revista Ciência Agronômica, v.34, n.2, p.247-51, 2003. INNIS, D.Q. Intercropping and the scientific basis of the traditional agriculture. London: Intermediate, 1997. 179p. MADUEÑO-BOX, M. Cultivo de plantas medicinales. Madri: Labor, 1973. 490p.

MAIA, N.B. Produção e qualidade do óleo essencial de duas espécies de menta cultivadas em soluções nutritivas. 1998. 105p. (Tese Doutorado) - Escola Superior de Agricultura Luiz de Queiroz, USP, Piracicaba. MARTINS, E.R. et al. Plantas medicinais. 3.ed. Viçosa: Editora UFV, 2000. 220p.

MORAES, A.A.; VIEIRA, M.C.; HEREDIA ZÁRATE, N.A. Produção de capuchinha e repolho, cultivada solteira e consorciada, com e sem cobertura do solo com camade-frango semidecomposta. Horticultura Brasileira, v.23, n.2, supl., 2005. CD-ROM.

MÜELLER, S. et al. Épocas de consórcio de alho com beterraba perante três manejos do mato sobre a produtividade e o lucro. Pesquisa Agropecuária Brasileira, v.33, n.8, p.1361-73, 1998.

OLASANTAN, F.O.; EZUMAH, H.C.; LUCAS, E.O. Effects of intercropping with maize on the micro-environment, growth yield of cassava. Agriculture, Ecosystems and Environment, v.57, p.149-58, 1996.

RAMOS, S.J. et al. Produção de matéria seca e óleo essencial de menta sob diferentes doses de fósforo. Revista Brasileira de Plantas Medicinais, v.8, n.1, p.9-12, 2005.

REZENDE, B.L.A. et al. Viabilidade econômica das culturas de pimentão, repolho, alface, rabanete e rúcula em cultivo consorciado, na primavera-verão, Jaboticabal, Estado de São Paulo. Informações Econômicas, v.35, n.3, p.22-37, 2005.

RODRIGUES, V.E.G.; CARVALHO, D.A. Plantas medicinais no domínio dos cerrados. Lavras: UFLA FAEPE, 2001. 180p.

SANTOS, R.H.S. Interações interespecíficas em consórcio de olerícolas. 1998. 129p. Tese (Doutorado em Fitotecnia) - Universidade Federal de Viçosa, Viçosa. SINGH, M. Effect of nitrogen and irrigation regimes on the yiels and quality of sweet basil (Ocimum basilicum L.). Journal of Spices and Aromatic Crops, v.11, n.2, p.151-4, 2002.

TRENBATH, B.R. Plant interactions in mixed crop communities. In: PAPENDICK, R.I. (Ed.). Multiple cropping. Wiscosin: American Society of Agronomy, 1975. p.129-69.

VIEIRA, C. O feijão em cultivos consorciados. Viçosa: UFV. 134p. 1989.

VIEIRA, M.C. et al. Produção de arruda e cenoura em cultivo solteiro e consorciado sob diferentes arranjos de plantas. Horticultura Brasileira, v.23, n.2, supl., 2005. CD ROM. 